\title{
Virtually Real, But Not Quite There: Social and Economic Barriers to Meeting Virtual Reality's True Potential for Mental Health
}

OPEN ACCESS

Edited by:

Federica Pallavicini,

University of Milano-Bicocca, Italy

Reviewed by:

Caroline Hands,

University of Liverpool,

United Kingdom

Nikos Papadopoulos,

Aristotle University of Thessaloniki,

Greece

*Correspondence:

Daniel Pimentel

pimend@uoregon.edu

Specialty section: This article was submitted to Virtual Reality in Medicine, a section of the journal

Frontiers in Virtual Reality

Received: 27 November 2020 Accepted: 06 January 2021

Published: 17 February 2021

Citation:

Pimentel D, Foxman M, Davis DZ and Markowitz DM (2021) Virtually Real,

But Not Quite There: Social and Economic Barriers to Meeting Virtual

Reality's True Potential for Mental Health.

Front. Virtual Real. 2:627059. doi: 10.3389/frvir.2021.627059

\author{
Daniel Pimentel ${ }^{1,2 *}$, Maxwell Foxman ${ }^{2}$, Donna Z. Davis ${ }^{1,2}$ and David M. Markowitz ${ }^{2}$ \\ ${ }^{1}$ Oregon Reality Lab, School of Journalism and Communication, University of Oregon, Portland, OR, United States, ${ }^{2}$ School of \\ Journalism and Communication, University of Oregon, Eugene, OR, United States
}

Strategies to mitigate the spread of COVID-19, namely quarantine and social distancing protocols, have exposed a troubling paradox: mandated isolation meant to preserve wellbeing has inadvertently contributed to its decline. Prolonged isolation has been associated with widespread loneliness and diminished mental health, with effects compounded by limited face-to-face access to clinical and social support systems. While remote communication technologies (e.g., video chat) can connect individuals with healthcare providers and social networks, remote technologies might have limited effectiveness in clinical and social contexts. In this review, we articulate the promise of Virtual Reality as a conduit to clinical resources and social connection. Furthermore, we outline various social and economic factors limiting the virtual reality industry's ability to maximize its potential to address mental health issues brought upon by the pandemic. These barriers are delineated across five dimensions: sociocultural, content, affordability, supply chain, and equitable design. After examining potential short- and long-term solutions to these hurdles, we outline potential avenues for applied and theoretical research seeking to validate these solutions. Through this evaluation we seek to (a) emphasize virtual reality's capacity to improve mental health by connecting communities to clinical and social support systems, (b) identify socioeconomic barriers preventing users from accessing these systems through virtual reality, and (c) discuss solutions that ensure these systems can be equitably accessed via changes to existing and future virtual reality infrastructures.

Keywords: coronavirus, social connection, COVID-19, loneliness, mental health, virtual reality

\section{INTRODUCTION}

The COVID-19 pandemic has stressed the foundation of our institutions, from healthcare to education (Crawford et al., 2020; Greenberg et al., 2020), and its consequences have been farreaching. Globally, people are faced with health-related uncertainties (Will I get sick?), job insecurities (Will I lose my job?), and fear that distance from our social connections will become normative (When can I see my family safely?). A tacit concern also gaining steam relates to the pandemic's immediate and downstream effects on mental health. According to the Center for Disease Control, in August 2020 more than 40\% of United States adults reported "at least one adverse mental or behavioral health condition" such as anxiety, depression, stress related to the pandemic, or substance use to cope with those stresses (Czeisler et al., 2020). 
In such times of heightened anxiety or stress, the modus operandi for clinicians is to recommend cognitive, behavioral, and mindfulness interventions (Marchand, 2012). However, the inability to safely deliver in-person services during the pandemic, coupled with increased patient demand and limited practitioner bandwidth (Huskamp et al., 2018; Lo et al., 2020), represent key barriers to treatment. Individuals may therefore rely upon informal social support systems, such as friends and family, to cope with stressors, but the pandemic has largely reduced access to such sources of social support (Palmer et al., 2020). The barriers preventing clinical and social systems from meeting the needs of affected communities have thus shifted attention toward new strategies for remedying the pandemic-related decline in psychological well-being (Moreno et al., 2020).

Historically, information and communication technologies (ICTs) have empowered medical institutions to meet mental health needs with scalable solutions, from online support groups to web-based health screenings (Lal and Adair, 2014). Virtual Reality (VR) represents a recent ICT development with the potential to revolutionize clinical and social support because of how it leverages head-mounted displays (HMDs) to swap a user's real-world sensory experience with that of computer generated one (Bailenson, 2018). This immersion ultimately contributes to a subjective sense of "being there" (spatial presence; Steuer, 1992), and a feeling of "being with" others in a virtual environment (social presence; Bailenson et al., 2003). Moreover, VR enables high levels of interactivity, translating user inputs (e.g., dialogue, behavior) into virtual actions with causal influence (Kalyanaraman and Bailenson, 2019). Collectively, presence and interactivity help social interactions in VR evoke psychological/behavioral responses akin to their real-world equivalents (e.g., Kassner et al., 2012).

Given VR's ability to safely transport individuals to supportive environments, clinical or otherwise, we believe there is no better time for the technology to help with everyday mental health issues. And yet, VR is scarcely adopted for such purposes. This paper articulates how VR is primed to meet the growing need for mental health support (Singh et al., 2020), and how industry has yet to meet this moment head-on due to access and culture constraints. Here, we discuss the pandemic's impact on social isolation-particularly, barriers to clinical and social support-and offer recommendations to improve our capacity for mediated mental health resources during this crucial time.

\section{SOCIAL ISOLATION'S IMPACT ON CLINICAL AND SOCIAL SYSTEMS}

COVID-19's normalizing of extended periods of social isolation is uniquely problematic because (a) social connections are vital to maintaining physical and mental health (Eisenberger and Cole, 2012), and (b) over $25 \%$ of homes in developed nations are oneperson households (Klinenberg, 2016). The "new normal" of prolonged isolation has also led to a troubling increase in loneliness among adults (Killgore et al., 2020; Krendl and Perry, 2020; van Tilburg et al., 2020), or the subjective sense that one's social connections are deficient (Cacioppo and Patrick,
2008). While being alone does not directly imply loneliness, actual/perceived isolation and loneliness can negatively affect mental health (Holt-Lunstad et al., 2015; Loades et al., 2020; Luchetti et al., 2020).

Clinical treatments to mitigate loneliness and associated ailments (e.g., depression) range from one-on-one mindfulness training to group therapy (Cacioppo et al., 2015). Limited access to in-person treatments has led clinicians to pivot toward telemental health delivery methods, such as web-based therapy sessions (Zhou et al., 2020). Despite its accessibility and convenience, telemental health delivery can feel impersonal and might interfere with the patient-clinician relationship (Connolly et al., 2020). Alternatively, recent work comparing Skype- and VR-based mental health service delivery found VR outperformed telehealth modalities in terms of perceived effectiveness, realism, and connectedness to clinicians (Pedram et al., 2020).

\section{VIRTUAL REALITY'S CLINICAL POTENTIAL}

Early scholarship touted the benefits of using clinical VR applications to address mental health issues (Rizzo and Kim, 2005). Today, VR continues to be a valuable tool for practitioners seeking to remedy mental health disorders by facilitating remote connections and functioning as a standalone remedy to specific ailments (Rizzo, 2019; Imperatori et al., 2020; Mantovani et al., 2020; Spiegel, 2020). For example, VR has been used to treat depression and anxiety (Parsons and Rizzo, 2008; Zeng et al., 2018), PTSD (Rothbaum et al., 2001; Difede et al., 2006), and other mental health disorders (Riva et al., 2015; Valmaggia et al., 2016). In instances where clinical workforce supply may not meet patient demand, certain mental health services (e.g., counseling) may be facilitated by automated avatars, including (virtual) Sigmund Freud (Osimo et al., 2015). Compared to nonimmersive platforms, interactions with agents in VR contribute to a greater sense of social presence and perceived affective understanding (Guimarães et al., 2020). VR can also be a self-help solution to reduce psychological distress by engaging in mindfulness practices in relaxing environments (Riva et al., 2020). Therefore, VR provides patients with new access points for mental health care.

\section{VIRTUAL REALITY'S SOCIAL POTENTIAL}

The same affordances that make VR clinically effective also undergird long-held perceptions of the medium (and its predecessors) as revolutionizing human connection and socialization. Claims that VR could be "the next big thing for mental health" (Martin, 2019) emerged before COVID-19 (Srivastava et al., 2014). Previous work shows VR can help individuals form meaningful social bonds with distant others (Tarr et al., 2018; Wiederhold, 2018), cope with loneliness (Bahng et al., 2020), and improve mood (Browning et al., 2020). Moreover, VR applications designed for vulnerable populations to engage in social activities (e.g., singing) can contribute to mental 
well-being via heightened connectedness and enjoyment (Tamplin et al., 2020).

The success of VR's predecessors, screen-based games and social virtual worlds also suggest these platforms could be effective in alleviating social isolation and loneliness (Davis and Calitz, 2014). Since the pandemic's start, the virtual world Second Life, saw a resurgence in use globally (Dodd, 2020; Egan, 2020), leaving many to claim, "the confined are 'found' in virtual worlds" (Le Monde, 2020). Equal enthusiasm was expressed for game worlds such as Fortnite which also saw record numbers in the same timeframe (Egan, 2020). And while these platforms are designed to create community through social interaction, recreating that experience in an HMD has yet to reach broad adoption.

\section{BARRIERS TO WIDESPREAD VIRTUAL REALITY USE}

If the need for social interaction has spurred interest into virtual worlds, and the benefits of such interactions can be augmented by VR's unique affordances, one would expect industry-wide emphasis on shifting social systems onto immersive platforms. Yet, there remains a gulf between VR's potential, both as a palliative remedy and social network, and its widespread commercial use. The barriers responsible for sustaining this gap, we argue, can be categorized broadly across five dimensions: sociocultural, content, affordability, supply chain, and equitable design.

\section{Sociocultural}

Two major antecedents for VR adoption include "sociability" and "social warmth" (Jang and Park, 2019). From a consumer perspective, this implies VR adoption may be contingent on social content: the metaverse imagined in science fiction where users virtually connect with each other. Although social VR platforms have emerged such as AltSpace VR and Sansar, adoption remains relatively low (SteamCharts, 2020). Additionally, HMDs have long been tied to primarily solo gaming experiences, such as Nintendo's "Virtual Boy." The ties go deeper in the contemporary moment (Foxman, 2018; Foxman, 2019), with tools for VR production inculcating early adopters into gaming environments to successfully design and develop content. In other words, it is not simply that the gamer identity is baked in at the consumer level, but also the producer level. Associations between gaming and VR create consumer expectations of play over people, undercutting the medium's perception as a socialization tool. These parallels also risk delegitimizing VR as a mental health tool in the eyes of healthcare providers, as supported by the lack of insurance coverage for video game-based mental health interventions (Baranowski et al., 2016).

\section{Content}

Content creation and distribution on popular headsets requires working within the game industry, either through use of game engines such as Unity or Unreal, or distribution via digital marketplaces like Steam. This narrows choices for consumers: most VR content they encounter is embedded in entertainment. For instance, the most common genres of immersive-only content in the Steam marketplace included action and shooter games (Foxman et al., 2020). And, for a variety of reasons (including hardware), many of these experiences tend to be socially isolated single-player games (de Regt et al., 2020). Even when single-player games place users alongside automated virtual characters, these parasocial interactions are less effective at reducing loneliness compared to co-player VR experiences involving other users (Liszio et al., 2017). Thus, even if consumers associate VR with social connection, content facilitating multi-user interactions remains limited, limiting VR's capacity for social support.

\section{Affordability}

Economic and cultural norms from the industry can narrow, rather than foster, social cohesion, as well as hinder access to communities outside of gaming. A primary issue is hardware costs, which range from US\$300-US\$1500, and remain out of financial reach for most consumers. These financial hardships exacerbated by COVID-19 leave people with little to no means of accessing meaningful virtual experiences to connect with others during quarantine. This reality is born out of VR market projections predicting a somewhat paradoxical rise of immersive content due to consumer demand, while headset sales are expected to only account for $23 \%$ of overall revenue (down from roughly a third; SuperData, 2020). Similarly, while the VR healthcare market is expected to boom in the next five years-particularly for health technology startups-there is widespread acknowledgment that the healthcare system is slow to change (e.g., Petrara, 2020). Researchers may tout VR's benefits to individual therapy and healthcare (Wiederhold and Riva, 2019), but public adoption by healthcare workers can only come after significant infrastructure changes occur (e.g., internet connectivity, stronger case studies for cost savings; Marbury, 2020). Paired with trends suggesting continued increases in mental health expenditure (Olfson et al., 2019), it is unreasonable to expect that consumers will invest in a platform when its content is not ready to meet their socioemotional connection needs.

\section{Supply Chain}

Consumers who can afford headsets face an additional barrier: disruptions to global supply chains. Due to quarantine measures, hardware manufacturing and distribution experienced significant delays, making VR "hard to find, at the worst time" (Kuchera, 2020). The pandemic exposed supply chain fragility and the need to engage in more localized, agile production processes capable of meeting market needs (Nandi et al., 2021).

Beyond needing to revamp hardware production and distribution, consumers also face exclusionary practices on two fronts. First, the existing audience for VR is built around the stereotypical white male gamer prototype identified in the design, marketing and even leadership of VR companies (Golding, 2019; Harley, 2020). Second, VR's virtual supply chain is built on game 
development studios who produce content for consumer-facing virtual marketplaces. Despite efforts to democratize development via free platforms like Unity, the pipeline to virtual distribution remains bound to "the monopolizing tendencies of platformization" (Chia et al., 2020), and thus would benefit from a continued push toward open-source solutions. Doing so would ensure that a wider array of simulations, including those focused on cultivating social connection to mitigate loneliness, could be accessed by those who need them.

\section{Equitable Design}

The VR industry's exclusionary orientation has also resulted in disparities that extend beyond the point of purchase. Most VR users need a certain level of "game capital" (Consalvo, 2009), acquiring common game norms, skills, knowledge, and hardware to successfully use the headsets. For instance, controllers are challenging to novices, containing buttons familiar to gamers and/or designed around specific games (e.g., first-person shooters). Recent efforts to introduce more natural, intuitive user inputs have also been problematic. For example, while Oculus' "Controller-Free" mode leverages hand gestures instead of button inputs, users with medical conditions (e.g., tremor, amputees) are limited in their ability to access spaces that may bring them a reprieve. Additionally, if users can access VR and its few social spaces, it is common to find them heavily embedded with gaming imagery, trolls, and toxic behavior that works against seeking connection under quarantine. For VR to fulfill its potential for well-being, engaging in inclusive hardware/ software design will ensure those most vulnerable to the detrimental effects of loneliness, namely older adults (Hawkley and Capitanio, 2015) and those with disabilities (Olsen, 2018; Davis and Stanovsek, 2020), can benefits from the platform. Finally, optimizing content for equitable use also requires developers to account for fatigue: as extended use can cause physical discomfort when exceeding $30 \mathrm{~min}$, VR-based interventions should be optimized for such intervals and incorporate breaks (Thai et al., 2020).

\section{DISCUSSION}

Taken together, we call upon academics, industry leaders, and clinicians to take the relationship between social isolation and VR seriously. Evidence suggests VR is a promising tool capable of connecting humans to clinical and social support systems that may reduce the adverse effects of the pandemic. Yet, given the barriers identified herein, ensuring an equitable and effective implementation of VR-based solutions, clinical or otherwise, remains unclear. Thus, we propose the following recommendations for clinicians and industry leaders to improve the lives and mental health of global communities.

Equitable distribution of innovative healthcare technology is predicated on co-creation: inclusion of all stakeholders at all stages of a product's development (Nambisan and Nambisan, 2017). VR is inherently an interdisciplinary platform, informed by the fields of psychology, computer science, game studies, architecture, and among others. As such, developers and scholars alike should integrate the unique expertize of medical professionals to co-create infrastructure capable of safely and effectively rendering services (Ospina-Pinillos et al., 2018). Cocreation should also include those who will inevitably reap the psychological benefits of VR. Incorporating patient input during content development ensures that virtual experiences fit their needs. This is particularly true of older adults who face unique obstacles as it relates to accessing and benefitting from digital mental health interventions (Seifert et al., 2019). For this reason, in the short term, we caution against an overreliance on technology-based solutions for facilitating medical or social interactions because these may not be inclusive of older adults with limited comfort or access to these options.

The VR industry and its content creators must also address accessibility issues at a socioeconomic and technical level; there is an evident need to reduce barriers to entry for low-income and low-access populations. One approach may be for VR titles to adopt "freemium" business models, providing users free access to core features of an app with the option to pay for premium services (Hamari et al., 2017). Another solution is for researchers and designers to pair accessible hardware design with inclusive software features (see Steed et al., 2020). Immersive content is seldom capable of accommodating users with visual or physical impairments, as experiences often require visual cues and use of hand controllers. This has created inconsistent accessibility standards across HMDs (Cook et al., 2019), though it may be remedied by providing alternative input methods. For example, brain-computer interfaces have shown promise as alternatives to traditional user inputs (Lotte et al., 2012), along with refreshable braille displays (Tran et al., 2019), and standardizing modification features to account for visual, hearing, and motor impairments (Playstation, 2020). Indeed, scholars note that minor modifications to VR scenes (e.g., modulating luminance) can make VR experiences accessible to users with visual impairments (Powell et al., 2020). VR content creators must follow suit by placing accessibility first and ensuring the mental health benefits of VR experiences are available to all users, regardless of sensory and mobility limitations.

According to mood management theory, media consumption is heavily motivated by hedonic concerns of either maximizing pleasure or minimizing pain (Zillmann, 1988; Oliver, 2003). Given VR's capacity to effectively induce specific moods, and since such emotional responses can be more pronounced in VR compared to 2D content (Diniz Bernardo et al., 2020), VR as a mood manager is a viable designation. However, for this potential to be realized at scale, content should enable customization interfaces to empower users to manipulate their virtual environments and meet their emotional needs. Mood induction experiences should not exist as standalone apps that may otherwise clutter the virtual marketplace, and rather should be integrated into existing infrastructure, such as social VR applications.

When users are not actively seeking to manage their emotional states, emerging VR functionalities may help nudge users toward more optimal moods. Affective computing studies illustrate the capacity of mobile devices to discern human emotional states from various user data sources (Picard, 2016). Specific to VR, 
non-verbal data (e.g., posture) provide unprecedented opportunities to tailor content to users (Miller et al., 2020). It will be possible to actively model how people think and feel during a crisis and adjust virtual environments or content suggestions accordingly, much like the burgeoning mobile meditation app industry.

While a single technology may not remedy the psychological strain of COVID-19 and social isolation, VR's potential as a conduit to clinical and social support systems cannot be overstated. The recommendations highlighted herein prompt medical professionals, business leaders, developers, and scholars to consider important barriers impeding on successful development and deployment of VR content that contributes to the psychological well-being of users. It is our hope that this overview guides theoretical and applied research into VR's capacity for psychological well-being during crisis, further

\section{REFERENCES}

Bahng, S., Kelly, R. M., and McCormack, J. (2020). "Reflexive VR storytelling design beyond immersion: facilitating self-reflection on death and loneliness," in Proceedings of the $2020 \mathrm{CHI}$ conference on human factors in computing systems, April 25-30, 2020, Honolulu, HI, United States. Editor J. McGrenere and A. Cockburn (New York, NY, USA: Association for Computing Machinery), 1-13.

Bailenson, J. (2018). Experience on demand: what virtual reality is, how it works, and what it can do. 1st Edn. New York: W. W. Norton \& Company.

Bailenson, J. N., Blascovich, J., Beall, A. C., and Loomis, J. M. (2003). Interpersonal distance in immersive virtual environments. Pers. Soc. Psychol. Bull. 29 (7), 819-833. doi:10.1177/0146167203029007002

Baranowski, T., Blumberg, F., Buday, R., DeSmet, A., Fiellin, L. E., Green, C. S., et al. (2016). Games for health for children - current status and needed research. Games Health J. 5 (1), 1-12. doi:10.1089/g4h.2015.0026

Browning, M. H. E. M., Mimnaugh, K. J., van Riper, C. J., Laurent, H. K., and LaValle, S. M. (2020). Can simulated nature support mental health? Comparing short, single-doses of 360-degree nature videos in virtual reality with the outdoors. Front. Psychol. 10, 2667. doi:10.3389/fpsyg.2019.02667

Cacioppo, J. T., and Patrick, W. (2008). Loneliness: human nature and the need for social connection: New York, NY: W. W. Norton and Company, 317.

Cacioppo, S., Grippo, A. J., London, S., Goossens, L., and Cacioppo, J. T. (2015). Loneliness. Perspect. Psycho. Sci. 10 (2), 238-249. doi:10.1177/1745691615570616

Chia, A., Keogh, B., Leorke, D., and Nicoll, B. (2020). Platformisation in game development. Internet Policy Rev. 9 (4), 1-28. doi:10.14763/2020.4.1515

Connolly, S. L., Miller, C. J., Lindsay, J. A., and Bauer, M. S. (2020). A systematic review of providers' attitudes toward telemental health via videoconferencing. Clin. Psychol. Sci. Pract. 27 (2), e12311. doi:10.1111/cpsp.12311

Consalvo, M. (2009). Cheating: gaining advantage in videogames. Cambridge, Mass: MIT Press.

Cook, D. M., Dissanayake, D., and Kaur, K. (2019). "Virtual reality and older hands: dexterity and accessibility in hand-held VR control," in Proceedings of the 5th international ACM in cooperation HCI and UX conference on CHIuXiD'19, April 1-9, 2020, Jakarta Surabaya, Bali, Indonesia. Editors Y. Kurniawan, E. Sari, and A. Tedjasaputra (New York, NY: Association for Computing Machinery), 147-151.

Crawford, J., Butler-Henderson, K., Rudolph, J., Malkawi, B., Glowatz, M., Burton, R., and Lam, S. (2020). COVID-19: 20 countries' higher education intra-period digital pedagogy responses. J. Appl. Lear. Teach. 3 (1), 1-20. doi:10.37074/jalt. 2020.3.1.7

Czeisler, M. É., Lane, R. I., Petrosky, E., Wiley, J. F., Christensen, A., Njai, R., et al. (2020). Mental health, substance use, and suicidal ideation during the COVID19 pandemic - United States, June 24-30, 2020. Morb. Mortal. Wkly. Rep. 69 (32), 1049-1057. doi:10.15585/mmwr.mm6932a1

Davis, D. Z., and Calitz, W. (2014). Finding healthcare support in online communities: an exploration of the evolution and efficacy of virtual support groups. J. Virtual Worlds Res. 7 (3), e10161. doi:10.4101/jvwr.v7i3.7068 establishing its place among the growing suite of "positive technologies" (Riva et al., 2020).

\section{DATA AVAILABILITY STATEMENT}

The original contributions presented in the study are included in the article/Supplementary Material, further inquiries can be directed to the corresponding author.

\section{AUTHOR CONTRIBUTIONS}

Authorship order reflects individual contributions to the manuscript: DP, MF, DD, and DM.

Davis, D. Z., and Stanovsek, S. (2020). The machine as an extension of the body: when identity, immersion and interactive design serve as both resource and limitation for the disabled. Human Mach. Commun. 2

de Regt, A., Barnes, S. J., and Plangger, K. (2020). The virtual reality value chain. Bus. Horiz. 63 (6), 737-748. doi:10.1016/j.bushor.2020.08.002

Difede, J., Cukor, J., Patt, I., Giosan, C., and Hoffman, H. (2006). The application of virtual reality to the treatment of PTSD following the WTC attack. Ann. N. Y. Acad. Sci. 1071 (1), 500-501. doi:10.1196/annals.1364.052

Diniz Bernardo, P., Bains, A., Westwood, S., and Mograbi, D. C. (2020). Mood induction using virtual reality: a systematic review of recent findings. J. Technol. Behav. Sci. [Epub ahead of print]. doi:10.1007/s41347-02000152-9

Dodd, L. (2020). Second Life enjoys a surprising renaissance as social distancers flock to virtual worlds. Available at: https://www.telegraph.co.uk/technology/2020/03/ 26/second-life-enjoys-surprising-renaissance-social-distancers/ (Accessed March 26, 2020).

Egan, J. (2020). The pandemic is causing the rise of making real money from virtual worlds. Available at: https://www.businessinsider.com/covid-19-causes-risereal-money-virtual-jobs-2020-7 (Accessed July 25, 2020).

Eisenberger, N. I., and Cole, S. W. (2012). Social neuroscience and health: neurophysiological mechanisms linking social ties with physical health. Nat. Neurosci. 15 (5), 669-694. doi:10.1038/nn.3086

Foxman, M., Leith, A. P., Beyea, D., Klebig, B., Chen, V. H. H., and Ratan, R. (2020) "Virtual reality genres," in Extended abstracts of the 2020 annual symposium on computer-human interaction in play. Editor P. Mirza-Babaei and V. McArthur (New York, NY: Association for Computing Machinery), 237-241.

Foxman, M. (2018). Playing with virtual reality: early adopters of commercial immersive technology. ProQuest dissertation and thesis. New York, NY. doi:10.7916/D8M05NH3

Foxman, M. (2019). United we stand: platforms, tools and innovation with the unity game engine. Soc. Media Soc. 5 (4), 205630511988017. doi:10.1177/ 2056305119880177

Golding, D. (2019). Far from paradise: the body, the apparatus and the image of contemporary virtual reality. Convergence Inter. J. Res. New Media Technol. 25 (2), 340-353. doi:10.1177/1354856517738171

Greenberg, N., Docherty, M., Gnanapragasam, S., and Wessely, S. (2020). Managing mental health challenges faced by healthcare workers during COVID-19 pandemic. BMJ. 368, m1211. doi:10.1136/bmj.m1211

Guimarães, M., Prada, R., Santos, P. A., Dias, J., Jhala, A., and Mascarenhas, S. (2020). "The impact of virtual reality in the social presence of a virtual agent," in Proceedings of the 20th ACM International Conference on Intelligent Virtual Agents October 19-23, 2020, Scotland, United Kingdom (New York, NY: Association for Computing Machinery), 1-8.

Hamari, J., Hanner, N., and Koivisto, J. (2017). Service quality explains why people use freemium services but not if they go premium: an empirical study in free-toplay games. Int. J. Inf. Manage. 37 (1), 1449-1459. doi:10.1016/j.ijinfomgt.2016. 09.004 
Harley, D. (2020). Palmer Luckey and the rise of contemporary virtual reality. Convergence Int. J. Res. New Media Technol. 26 (5-6), 1144-1158. doi:10.1177/ 1354856519860237

Hawkley, L. C., and Capitanio, J. P. (2015). Perceived social isolation, evolutionary fitness and health outcomes: a lifespan approach. Phil. Trans. Royal Soc. B. Biol. Sci. 370 (1669), 20140114. doi:10.1098/rstb.2014.0114

Holt-Lunstad, J., Smith, T. B., Baker, M., Harris, T., and Stephenson, D. (2015). Loneliness and social isolation as risk factors for mortality: a meta-analytic review. Perspect. Psychol. Sci. 10 (2), 227-237. doi:10.1177/1745691614568352

Huskamp, H. A., Samples, H., Hadland, S. E., McGinty, E. E., Gibson, T. B., Goldman, H. H., et al. (2018). Mental health spending and intensity of service use among individuals with diagnoses of eating disorders following federal parity. Psychiatr. Serv. 69 (2), 217-223. doi:10.1176/appi.ps.201600516

Imperatori, C., Dakanalis, A., Farina, B., Pallavicini, F., Colmegna, F., Mantovani, F., et al. (2020). Global storm of stress-related psychopathological symptoms: a brief overview on the usefulness of virtual reality in facing the mental health impact of covid-19. Cyberpsychol. Behav. Soc. Networking. 23 (11), 782-788. doi: $10.1089 /$ cyber.2020.0339

Jang, Y., and Park, E. (2019). An adoption model for virtual reality games: the roles of presence and enjoyment. Telematics Inf. 42, 101239. doi:10.1016/j.tele.2019. 101239

Kalyanaraman, S., and Bailenson, J. (2019). Virtual reality in media effects. In Media effects: advances in theory and research. Editors M. B. Oliver, A. A. Raney, and J. Bryant. 4th Edn. Routledge. doi:10.4324/9780429491146-26

Kassner, M. P., Wesselmann, E. D., Law, A. T., and Williams, K. D. (2012). Virtually ostracized: studying ostracism in immersive virtual environments. Cyberpsychol. Behav. Soc. Networking. 15 (8), 399-403. doi:10.1089/cyber.2012.0113

Killgore, W. D. S., Cloonan, S. A., Taylor, E. C., and Dailey, N. S. (2020). Loneliness: a signature mental health concern in the era of COVID-19. Psychiatr. Res. 290, 113117. doi:10.1016/j.psychres.2020.113117

Klinenberg, E. (2016). Social isolation, loneliness, and living alone: identifying the risks for public health. Am. J. Publ. Health 106 (5), 786-787. doi:10.2105/AJPH. 2016.303166

Krendl, A. C., and Perry, B. L. (2020). The impact of sheltering in place during the COVID-19 pandemic on older adults' social and mental well-being. J. Gerontol. Ser. B. 76 (2), e53-e58. doi:10.1093/geronb/gbaa110

Kuchera, B. (2020). The best VR device is hard to find, at the worst time. Available at: https://www.polygon.com/2020/4/13/21218930/coronavirus-quarantine-oculusquest-prices-sold-out-facebook-vr (Accessed April 13, 2020).

Lal, S., and Adair, C. E. (2014). E-mental health: a rapid review of the literature. Psychiatr. Serv. 65 (1), 24-32. doi:10.1176/appi.ps.201300009

Le Monde "Second Life", "Minecraft" ... The "confined" are found in virtual worlds. Available at: https://www.lemonde.fr/pixels/article/2020/04/01/second-lifeminecraft-les-confines-se-retrouvent-dans-les-mondes-virtuels_6035182_4408996. html (Accessed April 1, 2020).

Liszio, S., Emmerich, K., and Masuch, M. (2017). "The influence of social entities in virtual reality games on player experience and immersion," in Proceedings of the 12th international conference on the foundations of digital games, August 14-17, 2020, Hyannis, MA, United States. Editor S. Deterding (New York, NY: Association for Computing Machinery), 1-10.

Lo, C. B., Bridge, J. A., Shi, J., Ludwig, L., and Stanley, R. M. (2020). Children's mental health emergency department visits: 2007-2016. Pediatr. 145 (6) e20191536. doi:10.1542/peds.2019-1536

Loades, M. E., Chatburn, E., Higson-Sweeney, N., Reynolds, S., Shafran, R., Brigden, A., et al. (2020). Rapid systematic review: the impact of social isolation and loneliness on the mental health of children and adolescents in the context of COVID-19. J. Am. Acad. Child Adolesc. Psychiatr. 59 (11), 1218-1239.e3. doi:10.1016/j.jaac.2020.05.009

Lotte, F., Faller, J., Guger, C., Renard, Y., Pfurtscheller, G., Lécuyer, A., et al. (2012). "Combining BCI with virtual reality: towards new applications and improved BCI," in Towards practical brain-computer interfaces. Editors B. Z. Allison, S. Dunne, R. J. R. LeebMillan, and A. Nijholt (Berlin, Heidelberg: Springer), 197-220.

Luchetti, M., Lee, J. H., Aschwanden, D., Sesker, A., Strickhouser, J. E., Terracciano, A., et al. (2020). The trajectory of loneliness in response to COVID-19. Am. Psychol. 75 (7), 897-908. doi:10.1037/amp0000690

Mantovani, E., Zucchella, C., Bottiroli, S., Federico, A., Giugno, R., Sandrini, G., et al. (2020). Telemedicine and virtual reality for cognitive rehabilitation: a roadmap for the COVID-19 pandemic. Front. Neurol. 11, 926. doi:10.3389/ fneur.2020.00926

Marbury, D. (2020). What does the future hold for AR and VR in healthcare?. Available at: https://healthtechmagazine.net/article/2020/11/what-does-futurehold-ar-and-vr-healthcare (Accessed November 23, 2020).

Marchand, W. R. (2012). Mindfulness-based stress reduction, mindfulness-based cognitive therapy, and zen meditation for depression, anxiety, pain, and psychological distress. J. Psychiatr. Pract. 18 (4), 233-252. doi:10.1097/01. pra.0000416014.53215.86

Martin, S. (2019). Reality might be the next big thing for mental health. Available at: https://blogs.scientificamerican.com/observations/virtual-reality-might-bethe-next-big-thing-for-mental-health/ (Accessed June 24, 2019).

Miller, M. R., Herrera, F., Jun, H., Landay, J. A., and Bailenson, J. N. (2020). Personal identifiability of user tracking data during observation of 360-degree VR video. Sci. Rep. 10 (1), 17404. doi:10.1038/s41598-020-74486-y

Moreno, C., Wykes, T., Galderisi, S., Nordentoft, M., Crossley, N., Jones, N., et al. (2020). How mental health care should change as a consequence of the COVID19 pandemic. Lancet Psychiatry 7 (9), 813-824. doi:10.1016/S2215-0366(20) 30307-2

Nambisan, S., and Nambisan, P. (2017). How should organizations promote equitable distribution of benefits from technological innovation in health care?. AMA J. Ethics 19 (11), 1106-1115. doi:10.1001/journalofethics.2017. 19.11.stas1-1711

Nandi, S., Sarkis, J., Hervani, A. A., and Helms, M. M. (2021). Redesigning supply chains using blockchain-enabled circular economy and COVID-19 experiences. Sustainable Prod. Consumption 27, 10-22. doi:10.1016/j.spc.2020.10.019

Olfson, M., Wang, S., Wall, M., Marcus, S. C., and Blanco, C. (2019). Trends in serious psychological distress and outpatient mental health care of us adults. JAMA Psychiatry 76 (2), 152-161. doi:10.1001/jamapsychiatry.2018.3550

Oliver, M. B. (2003). "Mood management and selective exposure," in Communication and emotion: essays in honor of dolf zillmann. Editors J. Bryant, R. Roskos-Ewoldsen, and J. Cantor (New York: Routledge), 85-106.

Olsen, J. (2018). Socially disabled: the fight disabled people face against loneliness and stress. Disability Soc. 33 (7), 1160-1164. doi:10.1080/09687599.2018.1459228

Osimo, S. A., Pizarro, R., Spanlang, B., and Slater, M. (2015). Conversations between self and self as Sigmund Freud - a virtual body ownership paradigm for self counselling. Sci. Rep. 5 (1), 13899. doi:10.1038/srep13899

Ospina-Pinillos, L., Davenport, T. A., Ricci, C. S., Milton, A. C., Scott, E. M., and Hickie, I. B. (2018). Developing a mental health eclinic to improve access to and quality of mental health care for young people: using participatory design as research methodologies. J. Med. Internet Res. 20 (5), e188. doi:10.2196/jmir.9716

Palmer, K., Monaco, A., Kivipelto, M., Onder, G., Maggi, S., Michel, J. P., et al. (2020). The potential long-term impact of the COVID-19 outbreak on patients with non-communicable diseases in Europe: consequences for healthy ageing. Aging Clin. Exp. Res. 32 (7), 1189-1194. doi:10.1007/s40520-020-01601-4

Parsons, T. D., and Rizzo, A. A. (2008). Affective outcomes of virtual reality exposure therapy for anxiety and specific phobias: a meta-analysis. J. Behav. Ther. Exp. Psychiatry 39 (3), 250-261. doi:10.1016/j.jbtep.2007.07.007

Pedram, S., Palmisano, S., Perez, P., Mursic, R., and Farrelly, M. (2020). Examining the potential of virtual reality to deliver remote rehabilitation. Comput. Hum. Behav. 105, 106223. doi:10.1016/j.chb.2019.106223

Petrara, D. (2020). Healthcare 4.0 will push AR and VR Healthcare Revenues to US\$11 billion in 2024. Available at: https://www.prnewswire.com/newsreleases/healthcare-4-0-will-push-ar-and-vr-healthcare-revenues-to-us11billion-in-2024-301147333.html (Accessed October 7, 2020).

Picard, R. W. (2016). Automating the recognition of stress and emotion: from lab to real-world impact. IEEE Multimedia 23 (3), 3-7. doi:10.1109/MMUL.2016.38

Playstation (2020). Accessibility options for the last of us Part II. Available at: https://www.playstation.com/en-us/games/the-last-of-us-part-ii-ps4/ accessibility/.

Powell, W., Powell, V., and Cook, M. (2020). The accessibility of commercial offthe-shelf virtual reality for low vision users: a macular degeneration case study. Cyberpsychol. Behav. Soc. Networking. 23 (3), 185-191. doi:10.1089/cyber.2019.0409

Riva, G., Botella, C., Baños, R., Mantovani, F., García-Palacios, A., Quero, S., et al. (2015). "Presence-inducing media for mental health applications," in Immersed in media: telepresence theory, measurement and technology. Editors M. Lombard, F. Biocca, J. Freeman, W. Ijsselsteijn, and R. J. Schaevitz (Cham: Springer), 283-332. 
Riva, G., Mantovani, F., and Wiederhold, B. K. (2020). Positive technology and COVID-19. Cyberpsychol., Behav. Soc. Networking. 23 (9), 581-587. doi:10. 1089/cyber.2020.29194.gri

Rizzo, A. S. (2019). "Clinical virtual reality in mental health and rehabilitation: a brief review of the future!," in Infrared technology and applications XLV. Editors G. F. Fulop, C. M. Hanson, and B. F. Andresen (Baltimore, MD: SPIE), 300.

Rizzo, A. S., and Kim, G. J. (2005). A SWOT analysis of the field of virtual reality rehabilitation and therapy. Presence Teleoperators Virtual Environ. 14 (2), 119-146. doi:10.1162/1054746053967094

Rothbaum, B. O., Hodges, L. F., Ready, D., Graap, K., and Alarcon, R. D. (2001). Virtual reality exposure therapy for Vietnam veterans with posttraumatic stress disorder. J. Clin. Psychiatry 62 (8), 617-622. doi:10.4088/JCP.v62n0808

Seifert, A., Reinwand, D. A., and Schlomann, A. (2019). Designing and using digital mental health interventions for older adults: being aware of digital inequality. Front. Psychiatry 10, 568. doi:10.3389/fpsyt.2019.00568

Singh, R. P., Javaid, M., Kataria, R., Tyagi, M., Haleem, A., and Suman, R. (2020). Significant applications of virtual reality for COVID-19 pandemic. Diabetes Metab. Syndr Clin. Res. Rev. 14 (4), 661-664. doi:10.1016/j.dsx.2020.05.011

Spiegel, B. (2020). VRx: how virtual therapeutics will revolutionize medicine: New York, NY: Basic Books.

Srivastava, K., Chaudhury, S., and Das, R. (2014). Virtual reality applications in mental health: challenges and perspectives. Ind. Psychiatry J. 23 (2), 83. doi:10. 4103/0972-6748.151666

SteamCharts (2020). SteamCharts, altspace VR. Available at: https://steamcharts. com/app/407060.

Steed, A., Ortega, F. R., Williams, A. S., Kruijff, E., Stuerzlinger, W., Batmaz, A. U., et al. (2020). Evaluating immersive experiences during Covid-19 and beyond. Interactions 27 (4), 62-67. doi:10.1145/3406098

Steuer, J. (1992). Defining virtual reality: dimensions determining telepresence. J. Commun. 42 (4), 73-93. doi:10.1111/j.1460-2466.1992.tb00812.x

SuperData (2020). SuperData XR Q2 2020 update. Available at: https://dfdnews. com/2020/07/28/superdata-xr-q2-2020-update/ (Accssed July 28, 2020).

Tamplin, J., Loveridge, B., Clarke, K., Li, Y., and Berlowitz, D. J. (2020). Development and feasibility testing of an online virtual reality platform for delivering therapeutic group singing interventions for people living with spinal cord injury. J. Telemed. Telecare 26 (6), 365-375. doi:10.1177/1357633X19828463

Tarr, B., Slater, M., and Cohen, E. (2018). Synchrony and social connection in immersive Virtual Reality. Sci. Rep. 8 (1), 3693. doi:10.1038/s41598-018-21765-4

Thai, K. T. P., Jung, S., and Lindeman, R. W. (2020). "On the use of "active breaks" to perform eye exercises for more comfortable VR experiences," in 2020 IEEE
Conference on Virtual Reality and 3D User Interfaces Abstracts and Workshops (VRW), March 22-26, 2020, Atlanta, GA, United States (IEEE), 468-476.

Tran, J. J., Gaule, P. T., Porter, J. R., III, Baker, C. M., Baker, D. T., Zahand, B. J., et al. (2019). Refreshable braille display accessory for a game controller. U.S. Patent and Trademark Office, U.S. Patent No 10,463,978.

Valmaggia, L. R., Latif, L., Kempton, M. J., and Rus-Calafell, M. (2016). Virtual reality in the psychological treatment for mental health problems: an systematic review of recent evidence. Psychiatry Res. 236, 189-195. doi:10.1016/j.psychres. 2016.01.015

van Tilburg, T. G., Steinmetz, S., Stolte, E., van der Roest, H., and de Vries, D. H. (2020). Loneliness and mental health during the COVID-19 pandemic: a study among dutch older adults. J. Gerontol. Series B, gbaa111. doi:10.1093/geronb/ gbaa111

Wiederhold, B. K., and Riva, G. (2019). Virtual reality therapy: emerging topics and future challenges. Cyberpsychol. Behav. Soc. Networking. 22 (1), 3-6. doi:10. 1089/cyber.2018.29136.bkw

Wiederhold, B. K. (2018). Virtual reality enhances seniors' health and well-being. Cyberpsychol. Behav. Soc. Networking. 21 (12), 739-740. doi:10.1089/cyber. 2018.29132.bkw

Zeng, N., Pope, Z., Lee, J., and Gao, Z. (2018). Virtual reality exercise for anxiety and depression: a preliminary review of current research in an emerging field. J. Clin. Med. 7 (3), 42. doi:10.3390/jcm7030042

Zhou, X., Snoswell, C. L., Harding, L. E., Bambling, M., Edirippulige, S., Bai, X., et al. (2020). The role of telehealth in reducing the mental health burden from COVID-19. Telemed. e-Health 26 (4), 377-379. doi:10.1089/tmj.2020.0068

Zillmann, D. (1988). Mood management through communication choices. Am. Behav. Sci. 31 (3), 327-340. doi:10.1177/000276488031003005

Conflict of Interest: The authors declare that the research was conducted in the absence of any commercial or financial relationships that could be construed as a potential conflict of interest.

Copyright (C) 2021 Pimentel, Foxman, Davis and Markowitz. This is an open-access article distributed under the terms of the Creative Commons Attribution License (CC $B Y)$. The use, distribution or reproduction in other forums is permitted, provided the original author(s) and the copyright owner(s) are credited and that the original publication in this journal is cited, in accordance with accepted academic practice. No use, distribution or reproduction is permitted which does not comply with these terms. 